\title{
Importância de aulas práticas no ensino de biologia na concepção de futuros docentes
}

\section{Importance of practical classes in the teaching of biology in the design of future teachers}

\author{
${ }^{1}$ Jonatha Anderson Fraga Egidio jonathaafegidio@gmail.com \\ 2 Bárbara Tapia Brito Oliveira \\ ${ }^{3}$ Stella Marys Meneses de Carvalho \\ ${ }^{4}$ Willian Rodrigues da Costa Marinho
}

\section{RESUMO}

O Ensino de Biologia através de aulas práticas permite a compreensão dos processos biológicos, bem como o papel da Ciência e tecnologia no mundo atual. O objetivo deste estudo foi identificar e discutir a concepção de futuros professores de Ciências/Biologia sobre o uso atividades práticas durante as aulas. Os procedimentos metodológicos envolveram um estudo qualitativo de cunho exploratório durante um curso realizado para futuros docentes do Consórcio Cederj/UENF. Analisando-se os dados nota-se que os graduandos entrevistados consideram importante o uso de atividades experimentais no processo de ensino aprendizagem, mas que há ainda alguns que não conseguem discernir o que é uma atividade prática ou em que momento devem ser utilizadas. Com isso, há muito ainda o que ser estudado e principalmente mudado na estrutura curricular das Universidades para que este tema possa ser abordado com maior vigor, produzindo futuros docentes cada vez mais preparados para o exercício do magistério.

Palavras-chave: Educação. Licenciatura. Aprendizado.

\begin{abstract}
The teaching of biology trough practical classes allows the understanding of biological processes, as well as the role of science and technology in today's world. The aim of this study was to identify and discuss the development of future Science/ Biology teachers on the use of practical activities during classes. The methodological procedures involve a qualitative study of an exploratory nature during a course conducted for future documents of the Cederj /UENF Consortium. Analyzing whether the data recorded in the case of interviewed students consider it important to use experimental activities in the teaching learning process, but that there are still some that are not discerned or whether it is a practical activity or when they will be used. As a result, the study is still very large and especially the curricular structure of the Universities for this topic, which can be addressed with greater vigor, producing future documents, increasingly prepared for the exercise of teaching.
\end{abstract}

Keywords: Education. Licenciatura. Learning.

1 Graduando em Ciências Biológicas - Universidade Estadual do Norte Fluminense Darcy Ribeiro (UENF).

2 Graduanda em Ciências Biológicas - Universidade Estadual do Norte Fluminense Darcy Ribeiro (UENF).

3 Mestranda em Ambiente, Sociedade e Desenvolvimento -UFRJ/NUPEM, Graduada em ciências Biológicas - Universidade Federal do Rio de Janeiro (UFRJ). Instituto de Biodiversidade e Sustentabilidade (NUPEM).

4 Doutorando em Ciências Ambientais e Conservação - UFRJ/NUPEM, Mestre em Ciências Ambientais e Conservação - UFRJ/NUPEM, Graduado em ciências Biológicas - UENF e Graduando em Engenharia Meteorológica - UENF. Universidade Federal do Rio de Janeiro (UFRJ). Instituto de Biodiversidade e Sustentabilidade (NUPEM) 


\section{INTRODUÇÃO}

No ensino de Biologia, durante o ensino médio, é importante que os conhecimentos sejam tratados de forma contextualizada, de modo que permitam que os alunos sejam capazes de lidar com as informações, compreendê-las, elaborá-las, refutá-las, quando for o caso, para compreender o mundo e nele agir com autonomia (BRASIL, 1998).

Baseado nisso, Krasilchik (2004), afirma que o ensino da Biologia contribui para a compreensão de "processos biológicos, da ciência e da tecnologia na vida moderna”. Sendo assim, o professor de Biologia tem um papel muito importante na construção do conhecimento, essa função de mediar o saber entre os alunos colabora com a disseminação do conhecimento sobre temas básicos, como doenças, saúde, corpo humano, alimentação, nossa associação ao meio ambiente, colaborando, assim, com o processo de amadurecimento social dos indivíduos.

Além disso, o ensino da Biologia valoriza atividades de experimentação, seja dentro da sala de aula, no laboratório ou no campo. Isso leva a reflexão de como o professor ensina Biologia para seus alunos, sobre o significado da aprendizagem e qual a importância da experimentação no ensino da Biologia (ROSITO, 2003).

As atividades práticas no ensino da Biologia têm um papel muito importante no processo de ensino e aprendizagem do aluno, permitindo que este explore uma diversidade de conteúdos que facilitem a compreensão dos conceitos apresentados na sala de aula durante as aulas teóricas (VIVEIRO, 2009).

Portanto, a educação deve ser privilegiada com diversas formas que potencialize um maior dinamismo e comprometimento, incluindo temas como vida, matéria, energia e movimento, evolução, formas de raciocínio, mudanças sociais entre outros (LACERDA, 1997).

De acordo com Freire (1997), para que haja a compreensão da teoria é preciso vivenciá-la. Logo, as atividades de experimentação tornam a aula dinâmica e prazerosa, permitem, algumas vezes, que os alunos manipulem equipamentos inovadores e por muitos desconhecidos, tornando mais significativo o processo de ensino aprendizagem.

Nesse momento observamos a importância de uma boa formação para os futuros professores. As Universidades, como centro de "difusão e promoção da ciência e da cultura", contribuem para a formação inicial dos novos educadores (DA PONTE, 2000). Entretanto o cotidiano escolar ignora algumas teorias educativas que os professores aprendem durante sua formação inicial, observa-se isso logo quando encaram a realidade escolar numa sala de aula (PRADA, 1997).

Esses futuros educadores devem ter em mente que sua formação é contínua, ela não acaba quando se obtém um diploma da graduação. Nesse sentido, faz-se necessário que estes busquem outros cursos extracurriculares para construir uma formação de qualidade e estejam aptos a relacionarem a teoria e a experimentação no ensino da Biologia, enriquecendo o processo de ensino-aprendizagem dos alunos (PRADA, 2010).

\section{OBJETIVOS}

Identificar e discutir a concepção de futuros professores de Ciências/Biologia sobre o uso atividades práticas como métodos facilitadores de ensino na formação do aluno. 


\section{METODOLOGIA}

As aulas foram ministradas em julho de 2019, no IFF- Instituto Federal Fluminense, Campus Macaé, localizado na Rod. Amaral Peixoto, Km 164 - Imboassica, Macaé - RJ. Dividimos as aulas em duas segundas-feiras, sendo ministradas no primeiro encontro as aulas com os temas: Ecologia e Embriologia com duração de duas horas de aula cada. No segundo encontro, os temas abordados foram: Genética e Botânica com duas horas de aula para cada tema ministrado. Ao todo foram 12 participantes do curso de férias promovido para alunos do curso de Licenciatura em Ciências Biológicas da Universidade Estadual do Norte Fluminense Darcy Ribeiro (UENF), do pólo CEDERJ localizado no município de Macaé no Rio de Janeiro. Ao final do curso foi elaborado um questionário com duas perguntas, através de um formulário Google, abordando a importância da aula prática em sala para facilitar e melhorar o ensino-aprendizagem dos alunos. Após a aplicação dos questionários, os dados foram tabulados em Excel para posteriores análises e confecção de gráficos e tabelas.

\section{RESULTADOS}

Analisando os resultados obtidos, foram selecionadas quatro respostas que julgamos ser importantes para discussão.

A primeira pergunta do questionário foi a seguinte: "Em sua opinião, qual a importância de trabalhar com atividades práticas no ensino de ciências/biologia?”, obtivemos as seguintes respostas.

Resposta 1: "Muito importante, pois é um método muito eficaz para o aluno aprimorar os conhecimentos adquiridos na aula teórica".

Resposta 2: "Faz o aluno compreender melhor a matéria. É algo diferente que vai entreter e ao mesmo tempo ensinar a matéria ao aluno”.

Resposta 3: "É fundamental, a ciência apresenta conceitos que transcendem o comum e o visível, assim, as aulas práticas aproximam os alunos dos conceitos que parecem abstratos e intocáveis”.

Resposta 4: “A prática é um complemento da teoria, assim, o estudante tem outra visão quando estão em campo, adquirindo mais experiência e fixando melhor o conteúdo, é mais eficiente quando pratica-se determinado assunto".

A segunda pergunta abordada no questionário foi: “Em sua opinião, um debate é uma aula prática?”, a partir disso, foram observadas as seguintes respostas.

Resposta 1: "Não, pois na aula prática nós experimentamos o que foi aprendido numa aula teórica”.

Resposta 2: “Sim, pois todo tipo de atividade além da parte teórica é uma atividade prática”.

Resposta 3: "Sim, pois são debates de ideias concebidas durante uma teoria”.

Resposta 4: "Sim, aulas práticas são um momento onde o aluno pode desenvolver de forma aplicável aquilo que é trazido de aulas teóricas”. 


\section{DISCUSSÃO}

A pesquisa desenvolvida por De Lima e Garcia (2011) indica que uma aula com atividades experimentais contribui para um melhor desempenho no aprendizado dos alunos do que aulas que não apresentam esse tipo de atividade. Esse fato está de acordo, por exemplo, com as respostas 1 e 3 da primeira pergunta quando os estudantes afirmam que "é um método muito eficaz para o aluno aprimorar os conhecimentos adquiridos na aula teórica" e que proporciona ao estudante uma melhor compreensão do conteúdo "aproximando" o mesmo de conceitos que parecem distantes.

Nas respostas 2 e 4 da primeira pergunta os entrevistados afirmam que a atividade prática entretém o educando, tornando-se assim um método eficiente no desenvolvimento de seu aprendizado. Assim como Salesse (2012) que, em sua pesquisa, aponta a experimentação como método de "fundamental importância para uma aprendizagem significativa, despertando um forte interesse entre os educandos”.

A palavra debate está relacionada a prática de discussão organizada sobre determinados assuntos, segundo o dicionário Houaiss (2015). Assim, entendemos que o debate é uma troca de ideias de experiências vividas ou adquiridas, sendo assim, um bom instrumento para ser utilizado como atividade de experimentação quando falamos, por exemplo, de temas como o teste de medicamentos em animais ou o uso medicinal de plantas consideradas drogas, fugindo da formalidade do professor como centralizador do conhecimento. As respostas 2, 3 e 4 podem ser apoiadas no trabalho de Viveiro (2009), elas consideram que o debate pode ser considerado uma atividade prática visto que ela promove a exploração de conteúdos apresentados por aqueles que participam da discussão, processo esse que facilita a compreensão de diversos conceitos abordados durante o processo de ensino aprendizagem.

Por ouro lado, a resposta 1 da segunda questão discorda das demais respostas quando afirma que em uma aula prática é experimentado o que foi visto numa aula teórica. Porém, como afirma Coracini (1998), a teoria é concebida através de conhecimentos prévios adquiridos através de experimentos práticos e nem sempre a prática precede a teoria.

\section{CONCLUSÃO}

Com essa pesquisa foi possível identificar que os graduandos entrevistados consideram importante o uso de atividades experimentais no processo de ensino aprendizagem, pois estas melhoram o desempenho escolar dos alunos permitindo que explorem melhor os conceitos abordados dentro do ensino de ciências e biologia.

Porém, mesmo compreendendo sua importância, alguns alunos da licenciatura ainda entendem como aula prática aquela que são ministradas apenas em laboratórios ou no campo, sendo necessário explorar melhor as concepções de aula prática e discutir esses aspectos ao longo de sua docência.

Assim, é importante que os cursos de licenciatura reconsiderem sua estrutura curricular de forma que sejam promovidas novas percepções que permitam ao licenciando vivenciar experiências de atividades práticas que desenvolva sua criatividade como futuro educador, estimulando - no a ser um docente crítico e inovador em sua metodologia de ensino. 


\section{REFERÊNCIAS}

BRASIL. Parâmetros Curriculares Nacionais: Ciências Naturais/ Secretaria de Educação Fundamental. Brasília: MEC/ SEF, 1998.

CORACINI, Maria José RF. A teoria e a prática: a questão da diferença no discurso sobre e da sala de aula. DELTA: Documentação de Estudos em Lingüística Teórica e Aplicada, v. 14, n. 1, p. 33-57, 1998.

DA PONTE, João Pedro. Por uma formação inicial de professores de qualidade. 2000. Tese de Doutorado. Universidade do Algarve.

DE LIMA, Daniela Bonzanini; GARCIA, Rosane Nunes. Uma investigação sobre a importância das aulas práticas de Biologia no Ensino Médio. Cadernos do Aplicação, v. 24, n. 1, 2011.

FREIRE. P. Pedagogia da autonomia. Rio de janeiro: Paz e Terra, 1997.

HOUAISS, Antônio; VILLAR, Mauro de Salles; FRANCO, Francisco Manoel de Mello. Dicionário Houaiss da língua portuguesa. ed. 1. Moderna: São Paulo. 2015.

KRASILCHIK, Myriam. Prática de ensino de biologia. EdUSP, 2004.

LACERDA G. Alfabetização científica e formação profissional. Educ. Soc. (60): 91 108, 1997.

PRADA, Luis Eduardo Alvarado. Formação participativa de docentes em serviço. Cabral Editora Universitaria, 1997.

PRADA, Luis Eduardo Alvarado; FREITAS, Thaís Campos; FREITAS, Cinara Aline. Formação continuada de professores: alguns conceitos, interesses, necessidades e propostas. Revista Diálogo Educacional, v. 10, n. 30, p. 367-387, 2010.

ROSITO, Berenice Álvares. O ensino de ciências e a experimentação. Construtivismo e ensino de ciências: reflexões epistemológicas e metodológicas, v. 3, p. 195-208, 2003.

SALESSE, Anna Maria Teixeira. A experimentação no ensino de química: importância das aulas práticas no processo de ensino aprendizagem. 2012.

VIVEIRO, Alessandra Aparecida; DINIZ, R. E. da S. Atividades de campo no ensino das ciências e na educação ambiental: refletindo sobre as potencialidades desta estratégia na prática escolar. Ciência em tela, v. 2, n. 1, p. 1-12, 2009. 